\title{
How successful is color flow mapping and pulsed Doppler studies in predicting histologically confirmed benign and malignant adnexal masses in perimenopausal women
}

\author{
Souptik Gangopadhyay ${ }^{1 *}$, Partha Sarathi Chakraborty ${ }^{1}$, Archana Singh ${ }^{2}$
}

\author{
${ }^{1}$ Department of Obstetrics and Gynecology, SSKM Hospital, Kolkata, West Bengal, India \\ ${ }^{2}$ Department of Radiodiagnosis, SSKM Hospital, Kolkata, West Bengal, India
}

Received: 22 September 2017

Accepted: 27 October 2017

\author{
*Correspondence: \\ Dr. Souptik Gangopadhyay, \\ E-mail: drsouptik@gmail.com
}

Copyright: (c) the author(s), publisher and licensee Medip Academy. This is an open-access article distributed under the terms of the Creative Commons Attribution Non-Commercial License, which permits unrestricted non-commercial use, distribution, and reproduction in any medium, provided the original work is properly cited.

\section{ABSTRACT}

Background: Adnexal masses in perimenopausal women presents a specific diagnostic challenge because benign masses outnumbers malignant masses. Majority of adnexal masses are benign but $25 \%$ are malignant. The objective of this study was to see the effectiveness of transvaginal colour Doppler in predicting malignancy in adnexal masses in perimenopausal women.

Methods: Clinically detected adnexal masses were subjected to transabdominal ultrasound scan (for basic characterization of mass into solid, cystic, mixed) then transvaginal scan and neovascularization, resistivity index (RI) was measured. Subsequently all patients underwent laparotomy. Histopathological reports obtained, and correlation done between USG and histopathology.

Results: Among cystic masses neovascularization was present in 4 cases, among them benign and malignant masses were equal in number. Among mixed masses neovascularization was present in 17 cases 9 were malignant 8 benign, among solid masses all cases where neovascularization was detected were malignant. Neovascularization was absent in 12 cystic masses and 11 mixed masses, and all were benign. Kappa value calculated for tumour status and neovascularization is 0.610 which is substantially agreement with neovascularization as predictor of malignancy. Sensitivity, specificity, positive predictive value and negative predictive value of neovascularization for cystic masses are $100,85,50,100(\%)$ respectively. Sensitivity, specificity, positive predictive value and negative predictive value of neovascularization for mixed masses are 100, 57.89, 52.94, 100(\%) respectively. Sensitivity and positive predictive value of neovascularization for solid masses is $100(\%)$. Sensitivity specificity positive predictive value and negative predictive value of RI for cystic masses: 100, 92.8, 66.6, $100(\%)$ respectively. Sensitivity specificity positive predictive value and negative predictive value of RI for mixed masses: 77.7, 89.4, 77.7, 89.4(\%). Sensitivity positive predictive value of RI for solid masses $100 \%$. ROC curve analysis shows cut off value for differentiating between benign and malignant masses is 0.4 . Less than 0.4 has more chance of malignancy.

Conclusions: Transvaginal Doppler ultrasound must be done preoperatively for adnexal mass characterization.

Keywords: Adnexal mass, Neovascularization, Pulsitility index, Resistivity index

\section{INTRODUCTION}

Adnexal masses in perimenopausal women presents a specific diagnostic challenge because benign masses outnumber malignant masses. Majority of adnexal masses are benign but $25 \%$ are malignant. Determination of suspicion of malignancy is important in gynaecological practice to discriminate between benign and malignant tumours. ${ }^{1}$ Lack of reliable diagnostic tests is a major obstacle for better treatment of ovarian tumours, an 
accurate preoperative diagnosis provides better preoperative and intraoperative management and decreases morbidity and mortality of the patients.

Transvaginal sonography is widely used for the diagnosis as it is readily available and increased negative predictive value. $^{2-4}$ Optimal ultrasound technique and diagnostic criteria of malignant ovarian neoplasm for suspected ovarian malignancy are still controversial. Papillary formation on inner cyst wall and hyperechoic solid component are most satisfactory predictors. ${ }^{5,6}$ Ultrasound and morphologic parameters have a sensitivity and specificity of $80 \%$ and $93 \%$ that make this a standard for ovarian tumour diagnosis. ${ }^{7}$

Folkmans theory of neovascularization in which tumour cells elaborate tumour angiogenesis factor causing mitosis of endothelial cells and neocapillaries.

Benign tumours form blood vessels peripherally from host blood vessels. Malignant tumours form blood vessels centrally. ${ }^{8-10}$ Waveform analysis is based on the fact that malignant tumours are morphologically abnormal because they lack smooth muscles in their walls and demonstrate irregular course and arteriovenous shunt formation. Malignant tumours have low impedance which causes increased diastolic flow and systolic and diastolic variation. Such differentiation between benign and malignant tumours is achieved by quantifying these differences. ${ }^{11-14}$

Doppler flow measurement and assessment of tumour vascularity by Doppler increases the confidence with which correct diagnosis can be made. ${ }^{15-16}$ A comparison of various studies has shown that that RI 0.4 and PI $<1$ is highly suggestive of malignancy. ${ }^{17-23}$ Conventional USG lacks specificity to differentiate between benign and malignant masses. So, this study is conducted to see the effectiveness of colour flow mapping and pulsed Doppler studies in determining the nature of tumour.

\section{METHODS}

50 perimenopausal women attending OPD, Gynecology SSKM hospital with clinically and radiologically detected adnexal mass were included in the study after taking into consideration the inclusion and exclusion criteria.

\section{Inclusion criteria}

- Women between 38 and 55 years with clinically and sonographically detected adnexal masses

- Informed volunteers giving written consent

- Patients who are willing for regular follow-up.

\section{Exclusion criteria}

- Women with adnexal masses with hemodynamic instability
- Women with adnexal masses with chronic kidney and thyroid abnormalities denying surgery

- Women with poor general condition not fit for surgery

- Those with ectopic pregnancy and subserous fibroids confirmed as adnexal mass on sonography.

The present study was an observational study.

After detailed history and clinical examination, patients with suggestive history and clinically detected adnexal mass are informed about the study and consent taken. Then after proper counselling conventional USG done to detect and confirm adnexal mass.

Size of adnexal masses is detected by basic scan. For adnexal masses less than $10 \mathrm{~cm}$ TVS performed and those greater than $10 \mathrm{~cm}$ both TAS and TVS performed. Basic scan is used to differentiate the masses into solid, cystic and mixed.

To avoid luteal flow premenopausal women are examined in early follicular phase of menstrual cycle (D1-D10). Then RI and PI were calculated in centre and periphery of the mass for any vessel or in any place if mass is persistent for several months. The lowest RI PI values were used for analysis, that is vessel with lowest impedance.

Machine settings were adjusted to optimal Doppler parameters. Subsequently all women underwent laparotomy and histopathological examination of adnexal masses. Machine used was Philips HD 7 ultrasound machine.

Data would be summarized by routine descriptive statistics namely mean, standard deviation for numerical variables and categorical and other variables. Histopathological diagnosis would be considered as gold standard.

Ability of stated radiological investigations to predict malignancy would be quantified through calculation of sensitivity, specificity, and positive and negative predictive value. Attempt would also be made to calculate kappa coefficient.

Software used was MedCalc version 11.6 [Mariakerke, Belgium: MedCalc Software 2011.

\section{RESULTS}

50 perimenopausal women attending OPD, Gynecology SSKM hospital with clinically and radiologically detected adnexal mass were analysed in the study.

Mean age of the study group is 48.48 years. Mean parity and BMI are 2.32 and $26.2 \mathrm{~kg} / \mathrm{m}^{2}$ respectively. Family history and tobacco and OCP use present in $8 \%, 12 \%$, $18 \%$ of cases respectively (Table 1 ). 
Table 1: Patient's characteristics.

\begin{tabular}{ll} 
Characteristics & \\
Mean age & 48.48 years \\
\hline Mean parity & 2.32 \\
Mean BMI & 26.2 \\
\hline Relevant history & \\
\hline Family history & $8 \%$ \\
Tobacco use & $12 \%$ \\
\hline OCP use & $18 \%$ \\
\hline
\end{tabular}

Table 2 shows that main symptom of the patients was abdominal pain and distension, next to it is abnormal bleeding and others (jaundice, respiratory distress in advanced cases) in $26 \%$ of cases.

Table 2: Patients symptoms.

\begin{tabular}{|lll|}
\hline Abdominal pain and distension & $98 \%$ & $49 *$ \\
\hline Abnormal bleeding & $36 \%$ & $18 *$ \\
\hline Dyspepsia & $32 \%$ & $16 *$ \\
$\begin{array}{l}\text { Others (diarrhoea jaundice vomiting } \\
\text { dyspnoea) }\end{array}$ & $26 \%$ & $13 *$ \\
\hline Number of patients & & \\
\hline
\end{tabular}

Basic characterization of masses was done into solid cystic and mixed.

Majority of cystic masses were benign, and all solid masses were malignant, and out of 28 mixed masses 9 were malignant and rest benign (Table 3 ).
Table 3: Comparison of distribution of USG type between benign and malignant growths.

\begin{tabular}{|c|c|c|c|c|}
\hline Codes X & \multicolumn{4}{|c|}{ USG type } \\
\hline Codes Y & \multicolumn{4}{|c|}{ Tumour status } \\
\hline & \multicolumn{4}{|c|}{ Codes X } \\
\hline Codes Y & Cystic & Mixed & \multicolumn{2}{|l|}{ Solid } \\
\hline Benign & 14 & 19 & 0 & $33(66.0 \%)$ \\
\hline \multirow[t]{2}{*}{ Malignant } & 2 & 9 & 6 & $17(34.0 \%)$ \\
\hline & $\begin{array}{l}16 \\
(32.0 \%)\end{array}$ & $\begin{array}{l}28 \\
(56.0 \%)\end{array}$ & $\begin{array}{l}6 \\
(12.0 \%)\end{array}$ & 50 \\
\hline Chi-square & & \multicolumn{3}{|l|}{14.986} \\
\hline \multicolumn{2}{|c|}{ DF } & \multicolumn{3}{|l|}{2} \\
\hline \multicolumn{2}{|c|}{ Significance level } & \multicolumn{3}{|l|}{$\mathrm{P}<0.001$} \\
\hline Contingenc & efficient & \multicolumn{3}{|l|}{0.480} \\
\hline \multicolumn{5}{|c|}{$\begin{array}{l}\text { How much likely lesion to be malignant if it is solid } \\
\text { compared to non-solid? }\end{array}$} \\
\hline \multicolumn{3}{|c|}{ Solid } & \multicolumn{2}{|c|}{ Non-solid } \\
\hline \multicolumn{2}{|l|}{ Malignant } & 6 & \multicolumn{2}{|c|}{11} \\
\hline \multicolumn{2}{|l|}{ Benign } & 0 & 33 & \\
\hline
\end{tabular}

So more the lesion has solid component more likely the lesion is malignant.

Table 4 shows that 4 cystic masses showed neovascularization on USG and of them 2 were malignant. 17 mixed masses show edneovascularization, of them 9 were malignant. All solid masses were malignant and showed neovascularization.

Table 4: Details of correlation of neovascularization with histopathology in different categories of adnexal masses.

\begin{tabular}{|lllll|} 
Type of mass & Number of cases & Neovascularivation positive & \multicolumn{2}{l}{ HPE: histopathology } \\
Cystic & 16 & 4 & 2 & 2 \\
\hline Mixed & 28 & 17 & 8 & 9 \\
\hline Solid & 6 & 6 & 0 & 6 \\
\hline
\end{tabular}

Table 5: Details of correlation of neovasculatization with histopathology in different categories of adnexal masses.

\begin{tabular}{|lllll|}
\hline Type of mass & Number of cases & Neovascularivation alosent & \multicolumn{2}{l|}{ HPE: Histopathology } \\
\hline Cystic & 16 & 12 & Benign & Malignant \\
\hline Mixed & 28 & 11 & 12 & 0 \\
\hline Solid & 6 & 0 & 0 & 0 \\
\hline
\end{tabular}

Table 5 shows that 12 cystic masses showed absent neovascularization on USG and of them 12 were benign. 11 mixed masses showed absent neovascularization of them 11 were benign.

Correlation of tumour status and neovascularization Kappa value for presence of neovascularization during USG with malignant nature of the adnexal mass is .610 which means there is substantial agreement between neovascularization and malignant adnexal mass which is shown in Table 6.

Sensitivity, specificity, PPV, NPV of colour flow mapping (neovascularization) are 100, 85.7, 50, 100 (\%) respectively for cystic masses. For mixed masses sensitivity, specificity, PPV, NPV are 100, 57.8, 52.94, $100(\%)$ respectively. And for solid masses sensitivity and PPV are $100 \%$ each depicted in Table 7. 
Table 6: Correlation with neovascularization with tumour status.

\begin{tabular}{|llll|}
\hline Observer A & \multicolumn{3}{|c|}{ Tumour status } \\
\hline Observer B & \multicolumn{4}{c|}{ Neovascularization } \\
\hline Observer B & 0 & 1 & \\
\hline 0 & 23 & 0 & $23(46.0 \%)$ \\
\hline 1 & 10 & 17 & $27(54.0 \%)$ \\
\hline & 33 & 17 & 50 \\
\hline Kappa & $(66.0 \%)$ & $(34.0 \%)$ & \\
\hline Standard error & 0.610 & & \\
\hline 95\% CI & 0.102 & \\
\hline
\end{tabular}

Table 7: Diagnostic indices of neovascularization in detecting malignancy in adnexal masses.

\begin{tabular}{|lllll|}
$\begin{array}{l}\text { Type of } \\
\text { mass }\end{array}$ & Sensitivity & Specificity & PPV & NPV \\
\hline Cystic & 100 & 85.7 & 50 & 100 \\
\hline Mixed & 100 & 57.89 & 52.94 & 100 \\
\hline Solid & 100 & nil & 100 & nil \\
\hline
\end{tabular}

Analysis of RI (Doppler waveforms) shows that RI cut off value of 0.4 has a sensitivity $88.24 \%$, specificity $90.91 \%$, positive likelihood ratio of 9.71 , negative likelihood ratio of 0.13 as shown in ROC curve.

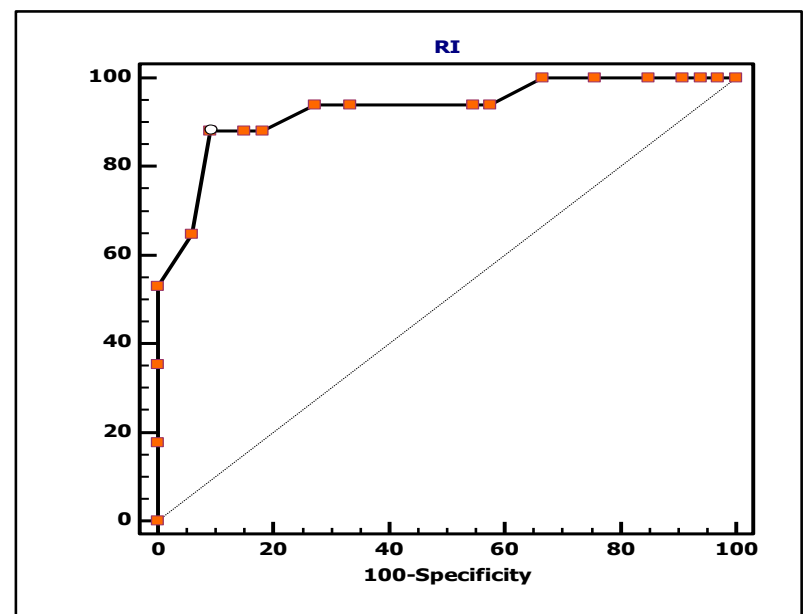

Area under the ROC curve (AUC): 0.929; Standard Error a: 0.0412 ; $95 \%$ Confidence Interval b: 0.819 to 0.982 ; $\mathrm{z}$ statistic: 10.418; Significance level P (Area=0.5): $<0.0001$

Figure 1: ROC curve analysis for malignancy prediction for $\mathbf{R I}$.

Analysis of PI (Doppler waveforms) shows that PI cut off value of 0.8 has a sensitivity $58.82 \%$, specificity $72.73 \%$, positive likelihood ratio of 2.16 , negative likelihood ratio of 0.5 as shown in ROC curve. So, RI (Doppler waveforms) is further considered for differentiating between benign and malignant masses. RI positive in 3 cystic masses, of them 2 were malignant. RI positive in 9 mixed masses of them 7 were malignant. All solid masses were RI positive and malignant shown in Table 8.

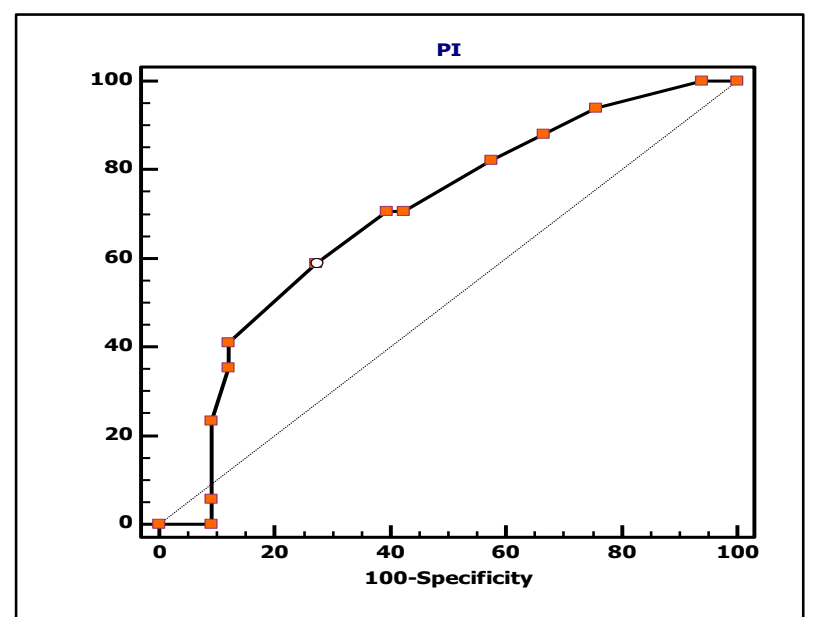

Area under the ROC curve (AUC): 0.698; Standard Error a: 0.0782 ; $95 \%$ Confidence Interval b: 0.552 to 0.820 ; z statistic: 2.530; Significance level P (Area=0.5): 0.0114

Figure 2: ROC curve analysis for malignancy prediction for PI.

Table 8: Details of correlation of Doppler waveforms (RI) with histopathology in different categories of adnexal masses.

\begin{tabular}{|lllll|}
$\begin{array}{l}\text { Type of } \\
\text { mass }\end{array}$ & Number & $\begin{array}{l}\text { RI } \\
\text { positive }\end{array}$ & Benign & Malignant \\
\hline cystic & 16 & 3 & 1 & 2 \\
\hline mixed & 28 & 9 & 2 & 7 \\
\hline solid & 6 & 6 & 0 & 6 \\
\hline
\end{tabular}

All RI negative masses were benign except mixed character masses in which 2 were malignant out of $17 \mathrm{RI}$ negative masses shown in Table 9.

Table 9: Details of correlation of Doppler waveforms(RI) with histopathology in different categories of adnexal masses.

\begin{tabular}{|lllll|}
$\begin{array}{l}\text { Type of } \\
\text { mass }\end{array}$ & Number & $\begin{array}{l}\text { RI } \\
\text { negative }\end{array}$ & $\begin{array}{ll}\text { Henign } \\
\text { Ben }\end{array}$ & Malignant \\
\hline cystic & 16 & 13 & 13 & o \\
\hline mixed & 28 & 19 & 17 & 2 \\
\hline solid & 6 & 0 & 0 & 0 \\
\hline
\end{tabular}

Table 10: Diagnostic indices of doppler waveforms in detecting malignancy in adnexal masses.

\begin{tabular}{|lllll|}
\hline $\begin{array}{l}\text { Type } \\
\text { of mass }\end{array}$ & sensitivity & specificity & PPV & NPV \\
\hline Cystic & 100 & 92.8 & 66.6 & 100 \\
\hline Mixed & 77.7 & 89.4 & 77.7 & 89.4 \\
\hline Solid & 100 & NIL & 100 & NIL \\
\hline
\end{tabular}

So, for cystic masses sensitivity, specificity, PPV, NPV of RI in detecting malignancy 100, 92.8, 66.6, 100(\%) 
respectively. For mixed character masses sensitivity, specificity, PPV, NPV of RI in detecting malignancy 77.7, 89.4, 77.7, 89.4 (\%) respectively. Sensitivity and PPV of RI in detecting malignancy for solid masses $100 \%$ each.

\section{DISCUSSION}

50 perimenopausal women with adnexal masses were assessed for the study. Mean age of patients was 48.84 years. Mean parity was 2.32 . Mean BMI was $26.2 \mathrm{~kg} / \mathrm{m}^{2}$ as shown in Table 1.

Family history of ovarian cancer was present in $8 \%$ of patients. Most common cancer detected in this group was serous and borderline cystadenocarcinoma. Tobacco use was present in $12 \%$ of patients and OCP use in $18 \%$ of patients. As per Table 2, abdominal pain with distension was most common symptom present in $98 \%$ of cases. Abnormal bleeding in $32 \%$ of cases. Among other symptoms jaundice, vomiting, diarrhoea, dyspnoea was present in $26 \%$ of cases.

Ultrasound whether transabdominal or transvaginal relies on morphological features for characterization of the type of mass. Morphology means wall thickness, loculi, septa, septal thickness. ${ }^{13,24,31}$ Many scoring systems have been proposed overall sensitivity ranges from 85 to $97 \%$ and specificity from 56 to $95 \%$. Various studies on morphology done by Ferazzi E, Kujrak A, Lerner JP, Tritsch T. ${ }^{25-31}$

Scoring system described by Sassone et al, is as follows: ${ }^{24}$

- Inner wall structure: smooth, irregular $(<3 \mathrm{~mm})$, papillarities, lesion mostly solid

- Wall thickness in $\mathrm{mm}$ : $<3 \mathrm{~mm},>3 \mathrm{~mm}$, and mostly solid lesions

- Septa: no septa, $<3 \mathrm{~mm}$ thickness, more than $3 \mathrm{~mm}$ thickness

- Echogenicity: low, mixed, high echogenicity, low echogenic with echogenic core.

Each is assigned a point and score $>9$ is high risk for malignancy.

In the present study masses are characterized into cystic, mixed and solid. As shown in Table 3, among 16 cystic masses 14 are benign, among 19 mixed masses 9 malignant and rest benign. All 6 solid masses were malignant. Chi-square test shows value 14.98, contingency coefficient is 0.48 , and $\mathrm{p}$ value is $<0.001$ which is highly significant. Also, that among malignant masses 6 were solid and 11 were non-solid. Neither of benign masses were solid. So as solidity of mass increases chances of malignancy increases. Odds ratio calculated is 37.87 . So, type of the mass is also important for determining whether it is benign and malignant. In order to improve sensitivity and specificity color flow mapping neovascularization was introduced. ${ }^{26,27,32}$

Neovascularization identifies these low resistance vessels in malignant tumors. There are continuous fluctuations in blood flow rather than pulsatile flow of blood in normal vessels. Various workers did study in this matter: Hata et al, Weiner et al, Kawai et al, and Zanetta et al etc. ${ }^{26,33,34}$

Hata et al conducted study with 16 number of adnexal masses. Of them 12 were neovascularization positive and 4 negative. Histopathology among positive masses 8 were malignant, 4 benign. All negative cases were benign. sensitivity, specificity, PPV, NPV 100, 50, 66.6, 100 (\%) respectively. ${ }^{26}$

Another study conducted by Zanetta et al, results were sensitivity, specificity, NPV $85, \quad 91, \quad 89 \quad(\%)$ respectively. ${ }^{35}$ Another study, by Sawicki et al specificity, PPV, NPV were 93.6, 66.8, 79.8. (\%). ${ }^{36}$

In the present study following facts about neovascularization:

Neovascularization is an important parameter in diagnosing the character of adnexal masses. Among cystic masses neovascularization was present in 4 cases, among them benign and malignant masses were equal in number. Among mixed masses neovascularization was present in 17 cases 9 were malignant 8 benign, among solid masses all cases where neovascularization was detected were malignant. Neovascularization was absent in 12 cystic masses and 11 mixed masses, and all were benign as shown in Table 4 and 5 .

Kappa value calculated for tumour status and neovascularization is 0.610 which is substantially agreement with neovascularization as predictor of malignancy as shown in Table 6.

Sensitivity, specificity, positive predictive value and negative predictive value of neovascularization for cystic masses are 100, 85, 50, $100(\%)$ respectively. Sensitivity, specificity, positive predictive value and negative predictive value of neovascularization for mixed masses are 100, 57.89, 52.94, $100(\%)$ respectively. Sensitivity positive predictive value of neovascularization for solid masses $100(\%)$ each as shown in Table 7.

To improve the detection rate Doppler waveforms with resistivity index pulsatility index was introduced for further characterization of masses. In the present study among cystic masses RI was positive in 3 cases of them 2 were malignant. Among mixed masses RI was positive in 9 masses of them 7 were malignant. All solid masses where RI were positive were malignant. Sensitivity specificity positive predictive value and negative predictive value of RI for cystic masses 100, 92.8, 66.6, $100(\%)$ respectively. Sensitivity specificity positive predictive value and negative predictive value of RI for 
mixed masses 77.7, 89.4, 77.7, 89.4 (\%). Sensitivity positive predictive value of RI for solid masses $100 \%$ each as shown in Table 8, 9 and 10.

Kujrak et al conducted a study in 14000 patients where 56 was found to be malignant. All but two showed abnormal Doppler, RI less than .4 with a Sensitivity specificity positive predictive value of $96.4,99.8,98.2$ (\%) respectively. ${ }^{37}$

In various studies sensitivity specificity varied from 50$100 \%$ and $46-100 \%$ respectively due to variation in thresholds in various studies. RI patterns in the present study shows that lowest value is .2 and highest value is 1.5. Arithmetic mean is $64.95 \%$ confidence interval for mean is $0.54-0.73$. Median 0.62, standard deviation is 0.3249 , standard error 0.04595 .

ROC curve shows that if RI .4 is taken as the demarcating line between benign and malignant adnexal masses then sensitivity is $88 \%$, specificity is $90 \%$ and positive likelihood ratio is 9.71 . As the demarcating value increases sensitivity increases but specificity and positive likelihood ratio decreases drastically as shown in curve.

PI patterns in the present study shows that lowest value is 0.5 and highest value is 1.4 . Arithmetic mean is $.97-95 \%$ confidence interval for mean is 0.90-1.04, median 1 , standard deviation is 0.2365 , Standard error 0.0345 . ROC curve shows that if PI 0.8 is taken as the demarcating line between benign and malignant adnexal masses then sensitivity is $58 \%$, specificity is $72 \%$ and positive likelihood ratio is 2.16 . As the demarcating value increases sensitivity increases but specificity and positive likelihood ratio decreases drastically as shown in curve.

Pulsatility index was not very much predictive of malignancy in the present study. $\mathrm{p}$ value is 0.0114 . Sensitivity, specificity, positive likelihood ratio and negative likelihood ratio are 58.82, 72.73, 2.16, and 0.57 respectively. In contrast RI has $\mathrm{p}$ value of $<0.0001$. Sensitivity, specificity, positive likelihood ratio and negative likelihood ratio are 88.24, 90.91, 9.71, and 0.13 respectively which is much better when compared to PI. Studies by Salem S, also shows the limitations of PI.

However, the pulsatility indexes showed considerable overlap between benign and malignant lesions, indicating that Doppler sonography has severe limitations in the differentiation of benign from malignant adnexal disease on the basis of low-impedance flow (pulsatility index $<1.0)$.

\section{Problems associated with Doppler analysis: ${ }^{38}$}

- Lack of standardizes criteria for differentiation benign and malignant waveforms

- In premenopausal women there is change in character of blood vessels in ovary, they become low resistance vessels, so they can appear malignant
- In absence of septa, solid areas it is difficult to detect RI, PI values

- In extreme inflammation like pelvic inflammatory disease and endometriosis there is abundance of low resistance vessels

Recently power Doppler has been introduced for better characterization of mass but due to more cost and requirement of skill it is limited to few centers. Now sonicated albumin microbubbles are introduced for better Doppler signals. ${ }^{39}$

\section{CONCLUSION}

Ultrasound remained the investigation of choice in preoperative assessment of the type of adnexal mass because it is widely available, non-invasive, and low cost.

Accurate preoperative diagnosis allows accurate operative planning and postoperative management, it prevents laparoscopic excision of masses in malignant tumours and inappropriate laparotomy done on benign masses in menopausal age group.

In the present study sensitivity for detecting malignancy was $100 \%$ for solid masses but for other type of masses prediction improved with application of Doppler parameters. So, USG must be used preoperatively for prediction of malignancy in adnexal masses in perimenopausal women.

\section{ACKNOWLEDGMENTS}

Authors are highly indebted to Prof. Partha Sararthi Chakraborty, their guide for his inspiration and willingness for making them motivated to work tremendously in this topic. Authors would like to thank Prof. Partha Sararthi Chakraborty, Department of Gynecology and Obstetrics, IPGME\&R, Kolkata, Prof. Sambunath Bandyopadhyay for his constant cooperation at all stages, Dr. Archana Singh, Assistant professor, Department of Radiodiagnosis and Prof. Avijit Hazra, Department of Pharmacology for his brilliant statistical analysis.

\section{Funding: No funding sources}

Conflict of interest: None declared

Ethical approval: The study was approved by the Institutional Ethics Committee

\section{REFERENCES}

1. Koonings PP, Campbell K, Mischell DR. Relative frequency of primary ovarian neoplasm: a 10 year review. Obstet Gynecol. 1989;74:921-6.

2. Andolf E, Jorgensen C. A prospective comparison of transvaginal and transabdominal ultrasound with surgical findings in gynecological disease. $\mathbf{J}$ Ultrasound Med. 1990;9:71-5. 
3. Disantis DJ, Scatarige JC, Given FT, Kemp G, Cramer MS. A prospective evaluation of transvaginal sonography for detection of ovarian disease. Am J Roentgenol. 1993;161:91-4.

4. Leibman AJ, Kruse B, Mcsweeney MB. Transvaginal sonography: comparison with transabdominal sonography in the diagnosis of pelvic masses. Am J Roentgenol. 1988;151:89-92.

5. Andolf E, Jorgensen C. A prospective comparison of clinical ultrasound and operative examination of female pelvis. J Ultrasound Medicine. 1988;7:61720.

6. Herrmann UJ Jr, Locher GW, Goldhirsch A. Sonographic patterns of ovarian tumors: prediction of malignancy. Obstet Gynecol. 1987;69(5):777-81.

7. Marret H. Doppler ultrasonography in the diagnosis of ovarian cysts: indications, pertinence and diagnostic criteria. J Obstet Gynecol Reprod Reprod Biol. 2001;30:20-33.

8. Kujrak A, Predanic M, Kupesik-Urek S, Jukie S. Transvaginal colour and pulsed Doppler assessment of adnexal tumour vascularity. Gynecol Oncol. 1993;50:3-9.

9. Dock W, Grabenwoger F, Metz V, Eibenberger K, Farres MT. Tumour vascularization: assessment with duplex sonography. Radiol. 1991;181:241-4.

10. Folkman J, Watson K, Ingber D, Hanahan D. Induction of angiogenesis from transition from hyperplasia to neoplasia. Nature. 1989;339:58-61.

11. Reles A, Wein U, Lichtenegger W. Transvaginal sonography and conventional sonography in preoperative assessment of adnexal masses. J Clin Ultrasound. 1997;25:217-25.

12. Emoto M, Iwasaki H, Mimura K, Kawarabayashi T Kikuchi M. Difference in angiogenesis in benign and malignant ovarian tumour, demonstrated by colour Doppler, immunohistochemistry and micro vessel density. 1997;80:899-907.

13. Maly Z, Riss P, Deutinger J. Localization of blood vessels and qualitative assessment of blood flow in ovarian tumors. Obstetric Gynecol. 1995:85(1):33-6.

14. Brustmann H, Naude S. Relevance of angiogenesis in benign and malignant tumours of ovary, a quantitative histologic study. Gynecol Oncol. 1997;67:20-6.

15. Cambell S, Bourne T, Bradley E. Screening for ovarian cancer by trans vaginal sonography and colour Doppler. Eur J Obstet Gynecol Reprod Biol. 1993;49:33.

16. Folkman J, Merler E, Abernathy C, Williams G. Isolation of tumor factor responsible for angiogenesis. J Exp Med. 1971;133:275-88.

17. Brown DL, Frates MC, Laing FC. Ovarian masses. can benign and malignant masses be differentiated with color and pulsed Doppler US?. 1994;190:333-6.

18. Carter J, Saltzman A, Fowler J, Carson L, Twiggs LB. Flow characteristics in benign and malignant gynecological tumours using transvaginal colour flow Doppler. Obstet Gynecol. 1994;83:125-30.
19. Jain KA. Prospective evaluation of adnexal masses with endovaginal grey scale duplex and colour Doppler US: correlation with pathologic findings. Radiol. 1994;191:63-7.

20. Levine D, Feldstein VA, Filly RA, Babcook CJ. Sonography of oarian masses: poor sensitivity of resistance index for identifying malignant masses. Am J Roentgenol. 1994;162:1355-9.

21. Salem S, White LM ,Lai J. Doppler sonography of adnexal masses:The predictive value of pulsitility index in benign and malignant disease. Am $\mathbf{J}$ Roentgenol. 1994;163;1147-50.

22. Weiner Z, Thaler I, Levron J, Lewit N. Uterine artery flow velocity waveforms and color flow imaging in women with perimenopausal and postmenopausal bleeding: Correlation to endometrial histopathology. Acta Obstet Gynecol Scand. 1993;59:743-9.

23. Rehn M, Lohmann K, Rempen A. Transvaginal ultrasonography of pelvic masses: evaluation of Bmode technique and Doppler ultrasonography. Am J Obstetric Gynecol. 1996;175(1):97-104.

24. Sassone AM, Tritsch TIE. Transvaginal sonographic characterization of ovarian disease: evaluation of a new scoring system to predict ovarian malignancy Obstet Gynecol. 1991;78:70-6.

25. Lerner JP, Timor-Tritsch, Federman A, Abramovich G- Transvaginal characterization of ovarian masses with an improved weighted scoring system. Am J Obstet Gynecol. 1994;170:81-5.

26. Hata K, Hata T, Manabe A, Sugimura K, Kitao M. A critical evaluation of transvaginal Doppler studies MRI and CA -125 in detecting ovarian cancer. Obstet Gynecol. 1992;80:922-6.

27. Franchi M, Beretta P, Ghezzi F, Zanaboni F, Goddi A, Salvatore S. Diagnosis of pelvic masses with transabdominal color Doppler, CA 125 and ultrasonography. Acta Obstet Gynecol Scand. 1995;74(9):734-9.

28. Schutter EMJ, Kenemans P. Diagnostic value of pelvic examination, ultrasound, and serum CA 125 in postmenopausal women with a pelvic mass. An international multicenter study. Cancer. 1994;74(4):1398-406.

29. Bushong SC. The physics and biology of diagnostic ultrasound. In: Athey PA, Hadlock FD, eds. Ultrasound in obstetrics and gynecology, $2^{\text {nd }}$ edition. St. Louis, CV Mosby; 1985:315-6.

30. Athey PA, Adnexa: Non-neoplastic cysts. In: Athey AP, Hadlock FD, eds. Ultrasound in Obstetrics and Gynecology, $2^{\text {nd }}$ edition. St Louis, CV Mosby; 1985:206-7.

31. Ferazzi E, Zanetta G, Dordoni D, Berlanda N: Transvaginal ultrasonographic characterization of ovarian masses. Comparison of five scoring system in a multicenter study. US Obstet Gynecol. 1997;10:192-7.

32. Brown DL, Doubilet PM, Miller FH, Frates MC, Laing FC, DiSalvo DN, at al. Benign and malignant ovarian masses: selection of the most discriminating 
gray-scale and Doppler sonographic features. Radiol. 1998;208(1):103-10.

33. Weiner J, Brandes JM, Beck D. Transvaginal sonography, colour Doppler, computed tomography screening, CA-125 as a routine follow up of women with pelvic tumour. Detection of recurrent disease. J Ultrasound Medicine. 1994;13:37-41.

34. Kawai M, Kano T. Transvaginal Doppler Ultrasound with colour flow imaging in the diagnosis of ovarian cancer. Obstet Gynecol. 1992;79:163-7.

35. Zanetta G, Lissoni A, Vergani P. Colour Doppler ultrasound in preoperative assessment of adnexal masses. Acta Obstet Gynecol.1994;73(8):637-41.

36. Sawicki W, Spiewankiewicz B, Cendrowski K, Stelmachów J. Preoperative discrimination between malignant and benign adnexal masses with transvaginal ultrasonography and colour blood flow imaging. 2001;22(2):137-42.

37. Kurjak A, Schulman H, Sosic A, Zalud I, Shalan H. Transvaginal ultrasound, color flow, and Doppler waveform of the postmenopausal adnexal mass. Obstet Gynecol. 1992;80(6):917-21.

38. Pellerito JS, Troiano RN, Quedens-Case C, Taylor KJ. Common pitfalls of endovaginal colour Doppler flow imaging. Radiograph. 1995;15(1):37-47.

39. Czekierdowski A, Stachowicz N, Smoleń A, Kotarski J. The use of 2-dimensional and 3dimensional color and power-Doppler in the diagnosis of blood flow indices of adnexal tumors. Gynecol Pol. 2006;77(4):296-306.

Cite this article as: Gangopadhyay S, Chakraborty PS, Singh A. How successful is color flow mapping and pulsed Doppler studies in predicting histologically confirmed benign and malignant adnexal masses in perimenopausal women. Int $\mathbf{J}$ Reprod Contracept Obstet Gynecol 2017;6:5440-7. 